TI 2013-102/ VIII

Tinbergen Institute Discussion Paper
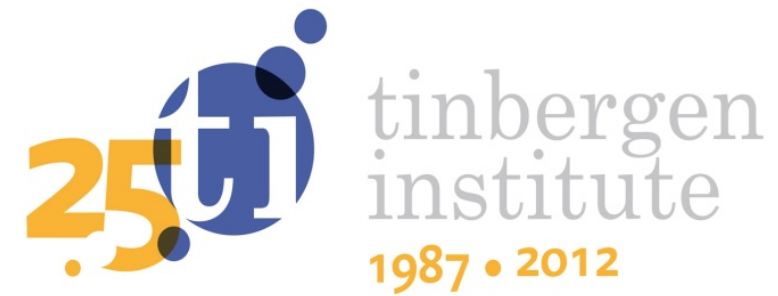

\title{
The Spatial-Institutional Architecture of Firms' Innovative Behaviour
}

\author{
Eric de Noronha Vazl \\ Teresa de Noronha Vaz² \\ Peter Nijkamp3
}

1 Ryerson University, Department of Geography, Toronto, Canada;

2 CIEO - Research Centre for Spatial and Organizational Dynamics, Faro, Portugal;

3 Faculty of Economics and Business Administration, VU University Amsterdam, Tinbergen Institute, The Netherlands. 
Tinbergen Institute is the graduate school and research institute in economics of Erasmus University Rotterdam, the University of Amsterdam and VU University Amsterdam.

More TI discussion papers can be downloaded at http://www.tinbergen.nl

Tinbergen Institute has two locations:

Tinbergen Institute Amsterdam

Gustav Mahlerplein 117

1082 MS Amsterdam

The Netherlands

Tel.: +31(0)205251600

Tinbergen Institute Rotterdam

Burg. Oudlaan 50

3062 PA Rotterdam

The Netherlands

Tel.: +31(0)10 4088900

Fax: $+31(0) 104089031$

Duisenberg school of finance is a collaboration of the Dutch financial sector and universities, with the ambition to support innovative research and offer top quality academic education in core areas of finance.

DSF research papers can be downloaded at: http://www.dsf.nl/

Duisenberg school of finance

Gustav Mahlerplein 117

1082 MS Amsterdam

The Netherlands

Tel.: +31(0)20 5258579 


\title{
The Spatial-Institutional Architecture of Firms’ Innovative Behaviour
}

\author{
Eric de Noronha Vaz ${ }^{1}$, Teresa de Noronha $\mathrm{Vaz}^{2}$ and Peter Nijkamp ${ }^{3}$
}

Pn589evtv

\begin{abstract}
In recent decades there have been an enormous number of studies about innovation systems, partly inspired by a great interest among policy makers in search for a solid scientific foundation and professional support to identify appropriate development strategies. Despite different perspectives, most studies highlight knowledge creation and innovation as the major drivers of change and growth. This consensus disappears, however, as soon as the complexity of innovation and knowledge are taken into consideration. Innovation goes far beyond new product or process development on account of its interactive nature, while knowledge often surpasses the firms' internal mechanisms, because, frequently, it is a spatially endogenous characteristic.

The present paper aims to offer a refreshing contribution to the above discussion and represents an effort to develop a novel model able to answer how institutions are relating to each other, drawing networks of innovation.

The available database comprises an extensive set of Portuguese innovative firms, spatially identified and able to engage in spatial connectivity in order to understand where and how strong the links are for innovation in Portugal, and to analyse the respective levels of geographical concentration or dispersion.
\end{abstract}

Keywords: innovation; firms

JEL categories: O31, D21

\footnotetext{
${ }^{1}$ Ryerson University, Department of Geography, Toronto, Canada

${ }^{2}$ CIEO - Research Centre for Spatial and Organizational Dynamics, Faro, Portugal

${ }^{3}$ VU University Amsterdam, Faculty of Economics and Business Administration, Amsterdam, and

Tinbergen Institute, the Netherlands
} 


\section{CONCEPTUAL FRAMING}

\section{The trajectories of technological development}

Over the past few decades, social scientists have developed a worldwide interest in the driving forces and socio-economic impacts of innovation and entrepreneurship (see Nijkamp 2009a, 2009b; Stimson et al. 2006). Innovation has turned out to be a critical parameter of human intelligence and of the cognitive ability of human kind. Nowadays, both factors are considered, to be the major drivers of socio-economic and technological change, able to stimulate the continuous production of new products or processes. To persuade society to continuously adopt such changes requires a systematic and integrative combination of knowledge assets managed within a framework of institutions, regulations, and some kind of socio-cognitive mechanisms (Hall et al. 2005).

The complexity of the innovation system is, in general, structured under conditions related to governance systems and their respective spatio-temporal industrial organization and their cognitive capacity. This argument recalls for Schumpeter's interpretation of the propensity of innovations to geographically group and generate clusters, which encourages innovation as a powerful instrument of growth. Against this background, innovation and its constituents have become of crucial interest, and, hence, tracing the complexity of governance systems is one of the key factors to explain the success of efforts to promote innovation. Countless efforts have been made to identify such factors: for example, some researchers have adopted a resource-based view of the firm by accepting the heterogeneous character of firms and emphasizing their strategic behaviour (Knudsen 1995; Noronha Vaz and Cesário 2008).

When knowledge became recognized as a key resource for firms and other economic agents, some authors demonstrated the essential role of linkages between industry and external research organizations for the successful transfer of technological knowledge among firms. This idea was later extended and referred to as the 'Triple Helix concept', a triangular interaction between the research community, governments and industries, which was seen as the solution to successful innovation (Doloreux and Parto 2005).

As linkages between institutions became long lasting and consistently robust, it became possible to address the consequent configuration in forms of networks and/or industrial clusters. In fact, a great variety of studies on clustering were influential in 
describing how and why institutions get together to react to competitive pressures. Westlund and Bolton (2006), for example, described clusters as geographical space with normative isomorphism, "where managers and decision makers follow similar values, cognitive references, perceptions, and experiences, therefore with a propensity to connect and pursue analogous patterns of organizational behaviour”.

In such a context, the concept of Regional Innovation Systems (RIS) was introduced as "a network of organizations, institutions and individuals, within which the creation, dissemination, and exploitation of new knowledge and innovation occurs" (Cooke et al. 2004). This concept influences the perception of the dynamics of clustering, and means that, for a given national or regional economy, technological and industrial development takes place by following certain trajectories determined by spatial systems traced by groups of linked firms, research organizations, policy institutions, government authorities, and financial actors (Teigland and Schenkel 2006).

\section{Networking, the strategic choices of firms and the spatial impacts}

Basically, the above-mentioned structures when observed from a global perspective tend to follow long-lasting technology trends that could, among other things, help explain the difficulties in reducing the different growth capacities among countries and regions. In general, the causes for this diverse behaviour and the propensity for disadvantages to have a cyclical nature in many lagging parts of the world have long attracted the attention of many researchers and policy makers (Hall and Wee 1995; Landabaso 1997).

As shown by the Italian School founded by the GREMI group (Camagni 1991, 1995a,

b) and, later on, by many other Northern European researchers, such as Asheim and Isaksen (2003), there is a direct contribution of individual firms or even of industrial clusters to foster regional growth. This finding has been emphasized even more in the research related to spillover effects, developed by, amongst others, Kaiser 2002, and Fischer 2006. But, as yet, many factors remain unsolved:

- There are ambiguous concepts related to the definition of the firms' environment. Either from a geographical or from a geometrical perspective, the market area of each firm and its dominant role vary in function or nature.

- Teigland and Schenkel (2006) argue that the firm’s environment should be defined by those agents involved in the historical path-dependent development of skills. 
- Other authors propose that the firm's environment is mostly responsible for all those strategic interactions that contribute to productive links within the firm's industrial structure.

- Finally, the firm's environment is highly influenced by the nature of the public institutions involved and their regulations, as they may help or obstruct interactions.

Assuming that the firm's environment is formed, and shaped coherently by the presence of significant linkages, functional clusters may be identified (see Porter 1998). And, assuming that, in spite of much uncertainty, where firms face new future needs for resources and clients, cluster formations are still emerging. In this case, it becomes important to detect whether the strategic decision of firms is internal or external driven: Langlois and Robertson (1995) first developed the idea that many questions related to firm strategy and firm boundaries are correlated. As assessed by Freel (1998), not much is understood about how technologically innovative firms grow, learn, or adapt to transformations taking place in their environments, therefore: (i) Will the strategic choices be solved by firms using market solutions? (ii) And if so, through which decision-making process will this take place?

Frequently, innovative firms accumulate knowledge through learning, as a process to reduce uncertainty, and not necessarily to obtain economies of scale. Therefore, by facilitating better decisions, knowledge acquisition could engage the entrepreneur in strategic learning - an option to absorb economies of scope rather than scale. Thus, the routines of innovative firms will be different from those of their non-innovative competitors.

Empirical studies often underline the role of the firms' environment as the local context within which firms develop their activities (Keeble 1997 and Freel 1998) in an interactive mode between the parts and the set (Noronha Vaz 2004). This demonstrates that organizational learning and institutional networking may be combined to boost the performance of innovative firms (Fagerberg 2003).

Occasionally, firms find possible solutions in specific networks for technological learning through external sources, and manage interfaces which help them to combine sources of technical know-how, information, and relations (Stough et al. 2007). In such cases, firms may also be organized in institutional local networks. In the remaining part of our study, we pay attention to the geographical and institutional support systems for innovative firms, with an evidence-based statistical modelling approach to Portugal. 


\section{MEASUREMENT OF FIRMS' INNOVATIVE BEHAVIOUR AT A REGIONAL SCALE}

\section{Technological regimes}

At the same time that innovation and entrepreneurship were accepted as major factors of growth, the measurement of innovative activities was also receiving much scientific and public attention. However, the measurements related to this systemic concept are still in the process of development. Since the 1990s, statistical surveys have supplied data concerning proxies such as $R \& D$ expenditures and the number of patented inventions. Sometimes such proxies were improved by adding up employment in R\&D-related activities or other data of a similar kind, but, so far, it cannot be confirmed that there is agreement about an unambiguous direct measure of innovation outputs.

Because the market structure influences innovative activities and the extent to which technological change has an impact on the size distribution of firms, a great part of the research performed is of an empirical nature, and mostly concerns advanced industrial countries. Rarely, have studies addressed rural or lagging areas (Noronha Vaz 2004). This issue dates back to 1991 (see Acs and Audretsch 1991), and invariably indicates that there are considerable ambiguities and inconsistencies in the results of empirical studies directly relating $R \& D$ or patents to innovation, particularly in less favoured areas.

Innovation output indicators have often been defined as a proxy for the total number of innovations. Kleinknecht and Bain (1993) proposed several methods for collecting data: postal surveys for self-assessment by managers of their innovations, or literature-based counting of innovations (in trade journals). Both these methods helped to highlight the issues, indicating related ways to work towards general inquiries. Applied in different countries - the first method in Great Britain, Norway, Denmark, Germany and the Netherlands, and the second one in United States, the Netherlands and Ireland - these methods proved to be quite subjective, making a scientific consensus difficult for the general use of the scientific community.

The European Community Innovation Survey (CIS) - implemented by EUROSTAT to collect firm-level data on inputs to, and outputs of, the innovation process across a wide range of industries, and across European Member-States and, occasionally, across regions - facilitated progress in comparative analyses of innovativeness across firms, regions, and nations. CIS has its limits, but it does provide 
evidence of the actual composition of inputs used by the firms to implement technological change. In terms of expenditures committed in the EU to innovative activities, formal R\&D in labs accounts for only 41per cent of the total, product design costs 22 per cent, and tooling up and training about per cent.

Also, at the macro-level, the available data suggest that firms are job creators and engines of economic growth. However, there is insufficient scientific evidence on the precise role that firms play in the growth mechanisms. Within the context of a learning economy, all enterprises have to adapt their technology to new standards of distribution and to logistic channels, in particular, when operating in an environment of intense competition. There, all categories of enterprises, which may belong to different regional or local innovation systems, are interacting and competing for innovative and market activities, using the same tools and the same knowledge flows (Lester, 2006).

The thesis adopted in our study is that regional or local innovation systems result from historical, path-dependent processes, with high degrees of institutional and organizational specificities - the technological regimes. Firms are embedded in a technological regime, and are operating according to the level and type of opportunities for innovations, the accumulation of technological knowledge, and the means of knowledge transmission. The examination of the technological regime of an industry makes it possible to predict, to a certain extent, the kind of enterprises that may innovate, because of the possibilities for protecting innovations, the strength of a dominant design, the nature and the continuity in the learning processes, and the tacitness of knowledge and the means for its transmission.

The above theoretical framing outlined above suggests that regional imbalances should be studied by means of obtaining a better understanding of the regional firms' capacity to dynamically innovate. The fact that such capacity may be quantitatively addressed and analysed helps to support the argument even further. Consequently, a key question for further investigation is to detect firms' innovation patterns, sort out their structures, and treat them as facilitators of regional or local growth.

\section{A meso-economic model to evaluate the structures of innovation}

A multilevel model able to improve the analytical tools is required for a better understanding of the complexity expressed by all the determinants of knowledge and innovation outlined above. Figure 1 shows the model in which knowledge assets are 
circulating simultaneously between the micro- and macro-levels of economic activity. The architecture of this model is as follows:

- An exterior cycle represents the global conditions for change, in general, mostly related to the macroeconomic conditions for growth such as GDP, employment, taxes, rates of interest, investment climate, and inflation;

- The intermediate cycle reproduces the knowledge diffusion taking place at the meso-economic level where institutional relationships occur in the form of: institutional proximity, technological learning, and regional or local conditions:

- There is a permeable boundary between the intermediate cycle and the interior one. Economic effects cross this boundary in the relevant domains associated with organizational management (entrepreneurship, strategic choices, creativity, clustering and networking) and regional policy (political choices, governance, regulation and environmental awareness) which determine an interior cycle which embodies knowledge application that may end up in new products and processes. The core of the cycle illustrates a sharp microeconomic component confined to critical aspects such as market competition, costs, prices, and marketing issues they are the ultimate facilitators of the success of new products and processes.

In this paper we concentrate our attention exclusively on the intermediate cycle, the meso-economic level. Our goal is to model the capricious, eventually frenetic, state of relationships occurring among institutions, happening as result of the three factors: proximity, learning, and cooperating, in the presence of regional or local conditions conducive to interaction.

We assume that a firm's proximity can be mapped out by a GIS application to a statistically significant sample of institutions, if possible by tracing their interaction with other actors which belong, or do not belong to the same sample. Learning and cooperating (measured as technological learning) and external conditions conducive to interaction are variables obtained by means of a direct approach to institutions, either by using questionnaires or by consulting the respective web-sites and with applications of content analyses for the primary data obtained. Figure 2 presents a model structure for measuring the firms' innovative behaviour in which spatial, institutional and environmental conditions are combined. This model is called the Firm Innovative Behaviour Model (FIBM). 


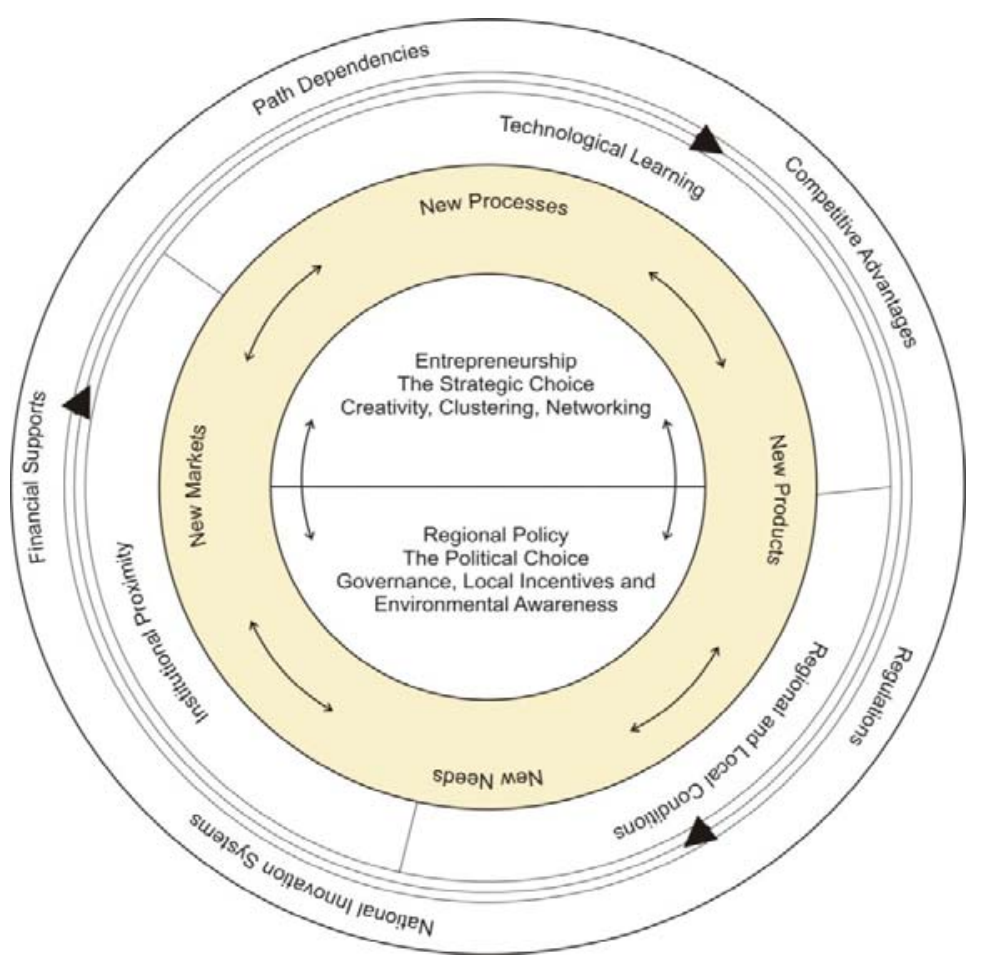

Figure 1. The knowledge circuit

Source: Noronha Vaz and Nijkamp (2009)

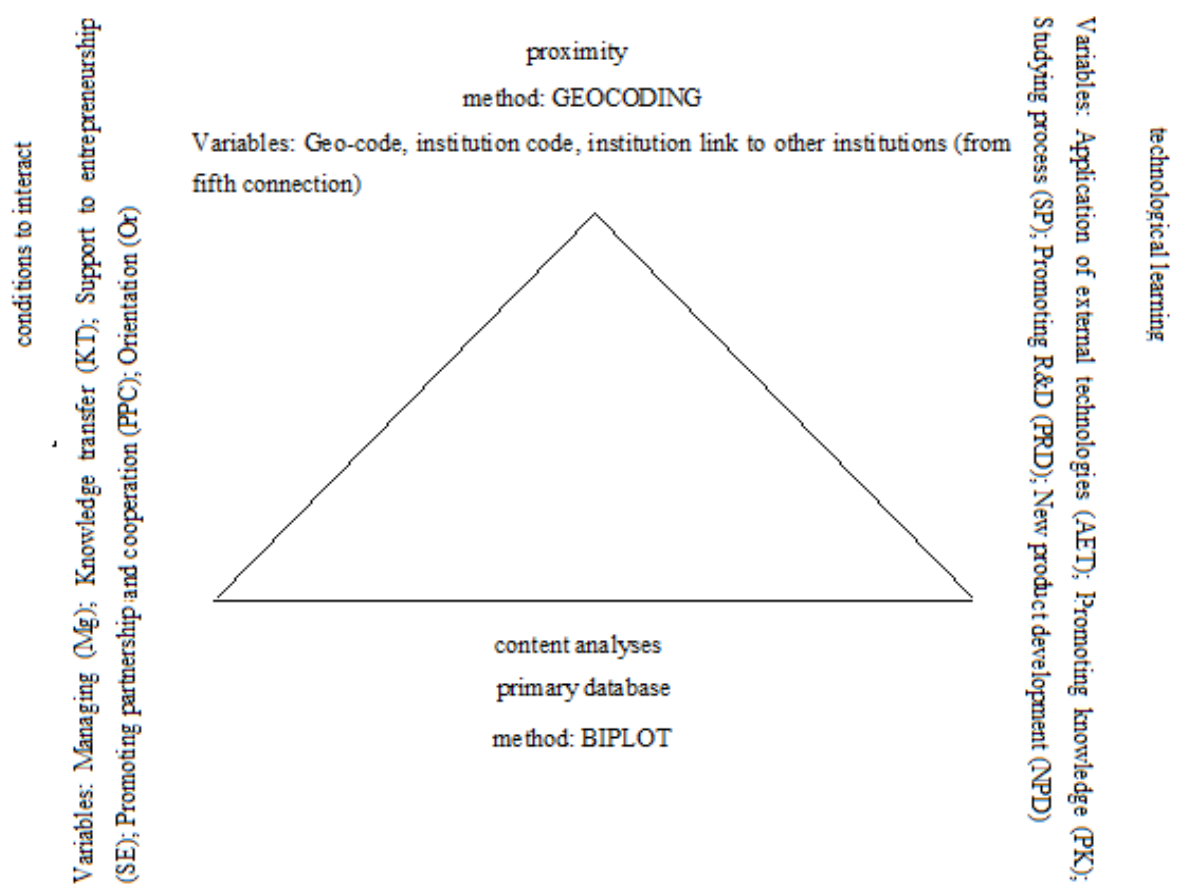

Figure 2. Firms' innovative behaviour model (FIBM) 


\section{APPLICATION OF THE FIRMS' INNOVATIVE BEHAVIOUR MODEL}

\section{Database}

Our investigation applies the previous model (FIBM) to an extensive set of Portuguese private and public institutions detected by their WebPage contents on innovation: 820 Internet sites were detected and interpreted, eventually resulting in a filtered sample of 623 institutions (which were considered to be able to provide reliable data through their respective websites). These institutions were classified into nine groups, each characterized by ten variables.

The selection of the variables was based on earlier developed research work (for more details see Noronha Vaz and Nijkamp , 2009, for the theoretical basis, and Vicente et al., 2010, for the measurement methods). The various constructed variables are assumed to be good proxies of factors favouring innovation, and are identified as attributes of innovation. To follow our meso-economic model assumptions, these ten attributes (defined as variables in the model) have been grouped (as in Figure 2) into two classes: 1) Variables for technological learning: Application of external technologies (AET); Promoting knowledge (PK); Studying process (SP); Promoting R\&D (PRD); New product development (NPD); 2) Variables for improving conditions conducive to interaction: Managing (Mg); Knowledge transfer (KT); Support to entrepreneurship (SE); Promoting partnership and cooperation (PPC); Orientation (Or).

As grouping factors the following institutions, the actors of innovation, have been considered: governmental agencies, associations, technological parks and science centres, R\&D organizations, entrepreneurship support entities, technological schools, university interfaces, financial institutes - as well as venture capitalists or high risk investors, and, finally, other institutions.

As pointed out in the theoretical model, a third group of variables was constructed to evaluate spatial proximity. These were formed by geo-coding each innovative institution ${ }^{4}$ and its respective links to other institutions with which each institution had maintained cooperation (from first to the fifth connection) of any sort for the period of time considered. All variables were derived by using two different but complementary methodologies: BIPLOT and SPATIAL CONNECTIVITY. The observed time period was the year 2006, so that the analysis has a static-comparative nature.

4 Innovative institutions were classified following the previous research in Vicente et al. (2010). 


\section{The research methods}

\section{A. The BIPLOT analyses}

The information used in our analysis was organized in an IxJ binary data matrix obtained from several innovation attributes, in which the I rows correspond to the above-mentioned 623 units (18 governmental entities, 297 companies, 70 associations, 20 technological parks and centres, 58 R\&D organizations, 48 entrepreneurship support entities, 12 technological schools, 80 university interfaces, and 14 other entities) and the $\mathrm{J}$ columns correspond to the above-mentioned 10 binary innovation characteristics scored as binary variables, viz. present or absent: (PK), (SP); (Mg); (PRD); (KT); (SE); (NPD); (PPC); (AET); (Or).

The applied statistical algorithm was described in Demey et al. (2008). The procedure to perform the External Logistic Biplot method is based on a Principal Coordinates Analysis, while, next, in a second step of the algorithm, a logistic regression model was used for each variable as illustrated, in Figure 3.

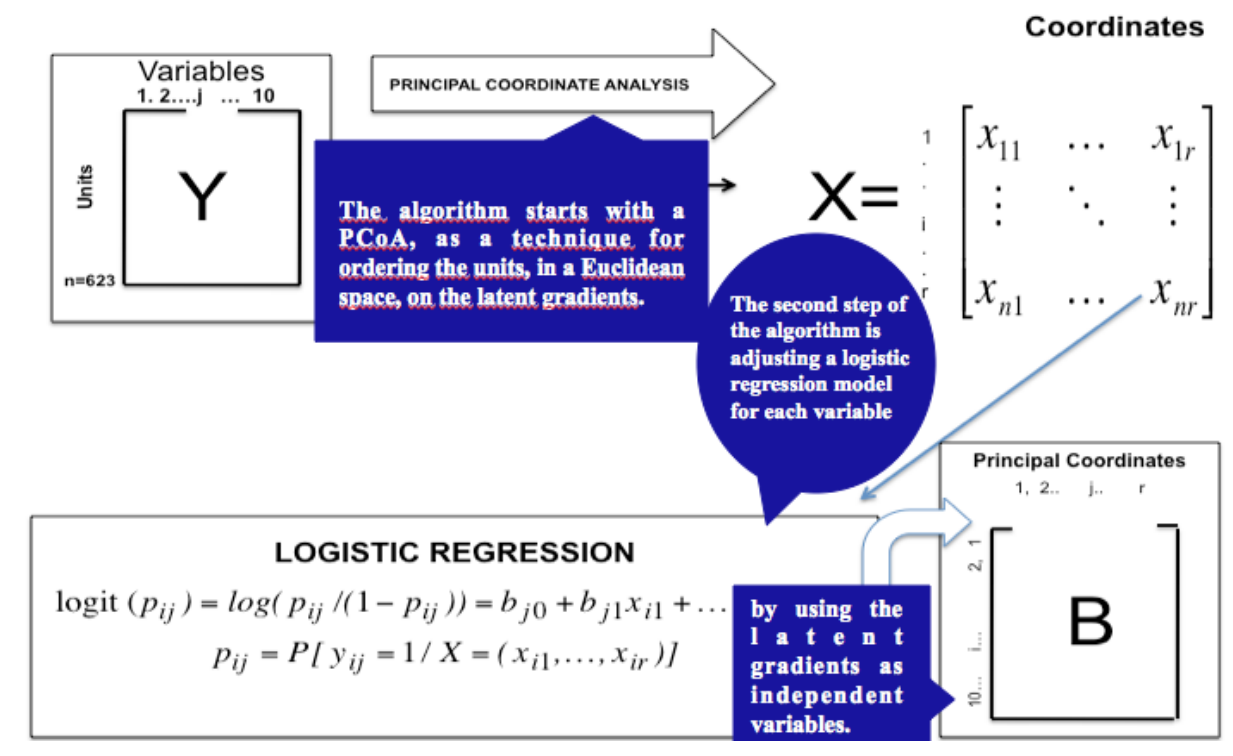

Figure 3. Steps for external logistic biplot

Source: Vicente et al. (2010) 
The geometric results represent the principal coordinate scores in a map where the regression coefficients act as vectors indicating the directions that best predict the probability of the presence of each variable.

According to the geometry of the linear Biplot for binary data (see VicenteVillardón et al. 2006), each variable is represented as a direction vector through the origin. For each variable, the ordination diagram can then be divided into two separate areas predicting presence or absence, while the two areas can be separated by a line that is perpendicular to the characteristic vector in the Biplot, and cuts the vector at the point which predicts a 0.5 probability.

The characteristics associated with the configuration are those that adequately predict the respective presences. Once the coordinates of the points which represent the entities (in our case the institutions) in the plane are obtained by the External Logistic Biplot, we can apply a K-Means analysis to identify the centroids of the resultant clusters. To produce an elegant solution, we may present a Voronoi diagram of the spatial relationships.

The method described above was applied to our data sample, thus eventually indicating the existing force field of the Portuguese innovation system. Figure 4A represents a Voronoi diagram of the existing spatial relationships. Four well defined clusters can be detected, each characterized by the presence or the absence of the different sets of variables. Cluster 1 is characterized by the presence of SP, AET, and NPD and the absence of SE; Cluster 2 is characterized by the presence of PK, PPC, OR, $\mathrm{KT}, \mathrm{Mg}$ and PRD, and the absence of SE; Cluster 3 is characterized by the presence of SE, PK, PPC, OR, KT, Mg and PRD and the absence of NPD, AET and SP. Cluster 3 is characterized by the absence of all the indexes of innovation. In terms of the characteristics of the firms, Cluster 1 has been identified as the cluster which contains the largest number of firms, and is therefore the most innovative one. Figure 4B represents the regional distribution of the firms of Cluster 1 in Portugal, showing that this cluster is mostly represented in the regions of Lisbon and Norte.

The application of this method can be extended to different observation levels, including the regional or the local level. If the databases provided are sufficiently available at a detailed geographical scale, it is possible to address even the local level. In such a case, the number of observations should be sufficient for the statistical application of the Biplot method. As this is not always the case, in particular in peripheral regions, the density of the entrepreneurial tissue constitutes the first major 
obstacle to the use of FIBM. Nevertheless, in the next subsection we will consider a more detailed geographical scale by using GIS methods.

\section{B. Spatial connectivity results}

The use of detailed spatial information has made it possible to understand the relations over space of different types of features (Jankowski, 1995). The spatial properties of location of activities and their respective impacts are still far from being completely understood, and have developed into a complex integration of economics, mathematics, and geography. A reason for this is the underlying complexity of the spatial patterns formed (Gustafson, 1998), and the connectivity established among the different agents in a complex network of interactions over space, as is illustrated traditionally in studies in ecology (Moilanen and Hanski, 2002).

The possibility to merge the configuration of features with networks may be assessed elegantly through generating a network which connects the spatial information concerning features. The connectivity of features in space, allows us to understand and foster the dynamics of collaborations of innovation from a spatial perspective. This was achieved by converting the provided street addresses of the businesses into a point vector in space. The address is categorized into its locational determinants: its street number, street name, and postal code. All this information was then added into ArcGIS 10.1 where the process of spatial connectivity - correspondent to the transformation of the address into a point - was carried out. The geocoded addresses were then exported into Google Earth, to match the consistency of the location with the attribute properties of the surrounding area, and the meta-data related to the geocoded feature were confirmed. 


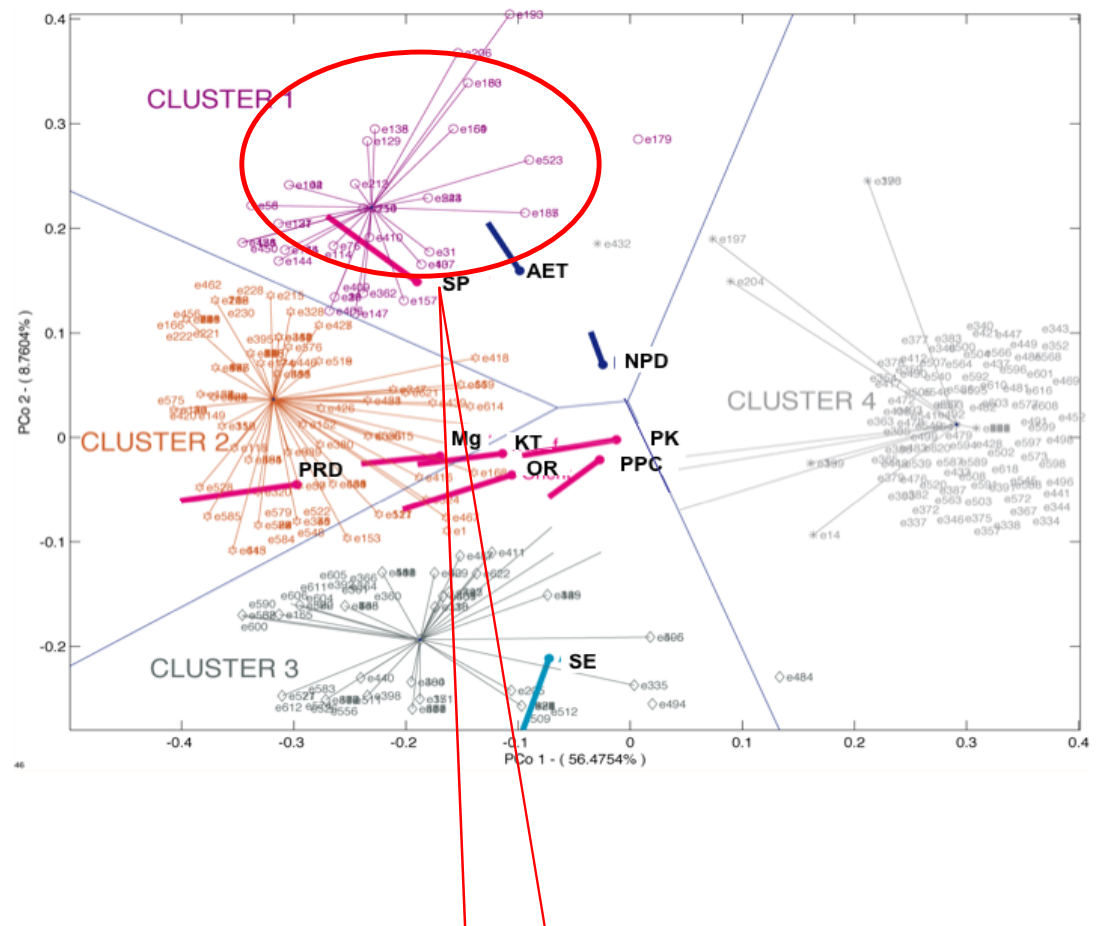

Figure 4A. Logistic BIPLOF and Voronoi diagram representations of spatial relationships and clusters of innovative firms in Portugal

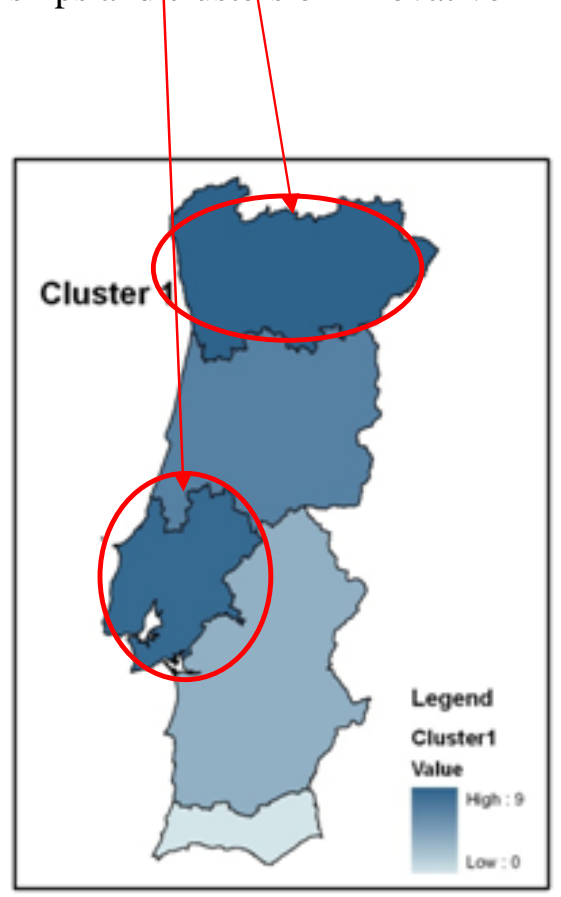

Figure 4 B. Regional distribution of Cluster 1 in Portugal 
In our empirical case, all the institutions belonging to Cluster 1, which were assumed to be the most innovative ones, were investigated, and their respective links reported up to the fifth connection - considered at any geographical level (local, national, or international). Because several institutions had no reported links, the sample that was used for our mapping procedure was reduced to 37 institutions in a total of 65 point features. The point features were then aggregated into groups corresponding to their partners, defining 15 aggregated groups. These groups of points were then connected by the relevance of the indicated partners, allowing us to establish a spatial understanding of small networks with spatial connectivity. These points were then converted into line segments and projected accordingly on the map.

Figures 5, 6 and 7 define the connections found at different scales: global, national, and local, in relation to the 50 most innovative institutions in Portugal, all included in Cluster 1 and considered to be the most innovative in the country. Only a few relationships are found to exist between the spatial component of countries and business innovators. In fact, most of the relationships, even at national level, are found only north the Tejo valley, with Lisbon and Porto being the main hubs for partnerships.

\section{General findings}

By detecting the types of patterns of structures of innovation in Portugal, many advantages and fragilities may be identified and clearly interpreted from a mesoeconomic perspective. In this context, the above-mentioned FIBM (see Figure 2) approach may be helpful.

- $\quad$ FIBM delivers a combined method able to evaluate the kind of connections underlying the innovation taking place in a certain region or country;

- In our particular case, Portugal, we can confirm an asymmetric flow distribution resulting from the connections from the most innovative institutions, which have based their innovation above all on the study of processes (SP), on the use of external technologies (AET); and on new product development (NPD);

- $\quad$ The asymmetric distribution shows that the most important flows are concentrated in the Lisbon area and Oporto (in the latter, case less intensively) and occasionally extend across Europe or to the USA. When observing the connections at the country level, we can find two hubs and a small focal point in the Centro region. The method allows us to pick up the individual institution responsible for this flow, and search for its innovative prospects. 
- Contrary to what was expected, not many connections start at the same point in the Lisbon region. This indicates that different institutions are able to sustain their own innovation paths in a structure that - although in itself is not very complex or elaborated - represents inter-connections at an elaborated level.

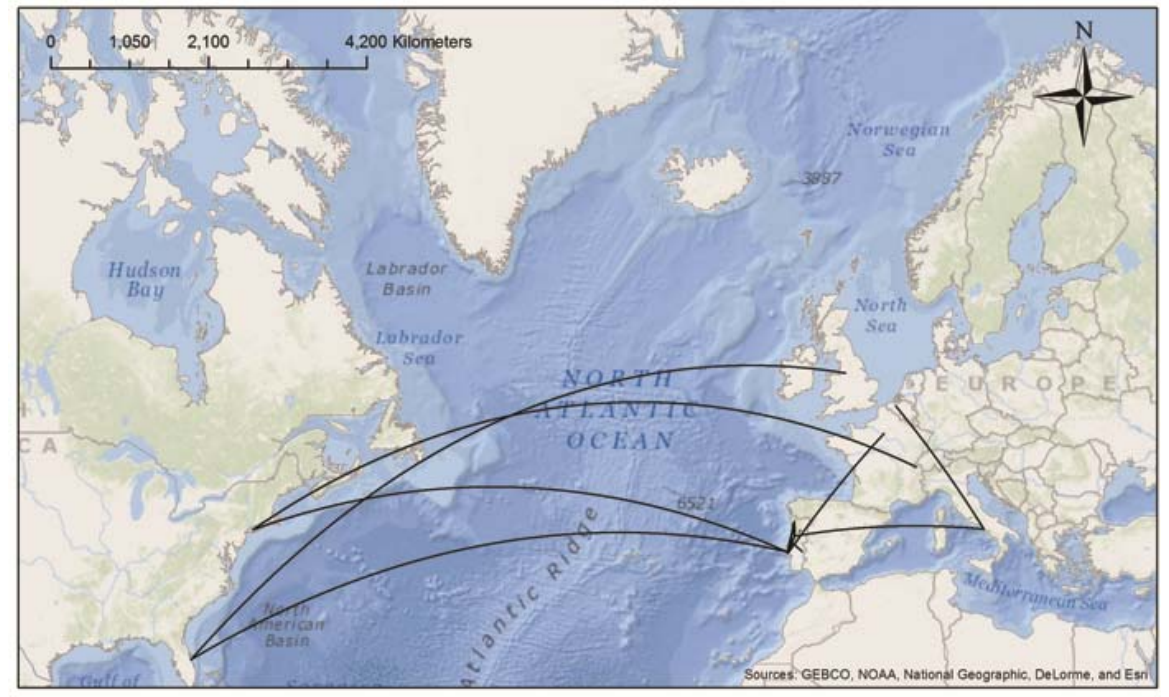

Figure 5. Flow design for international connections

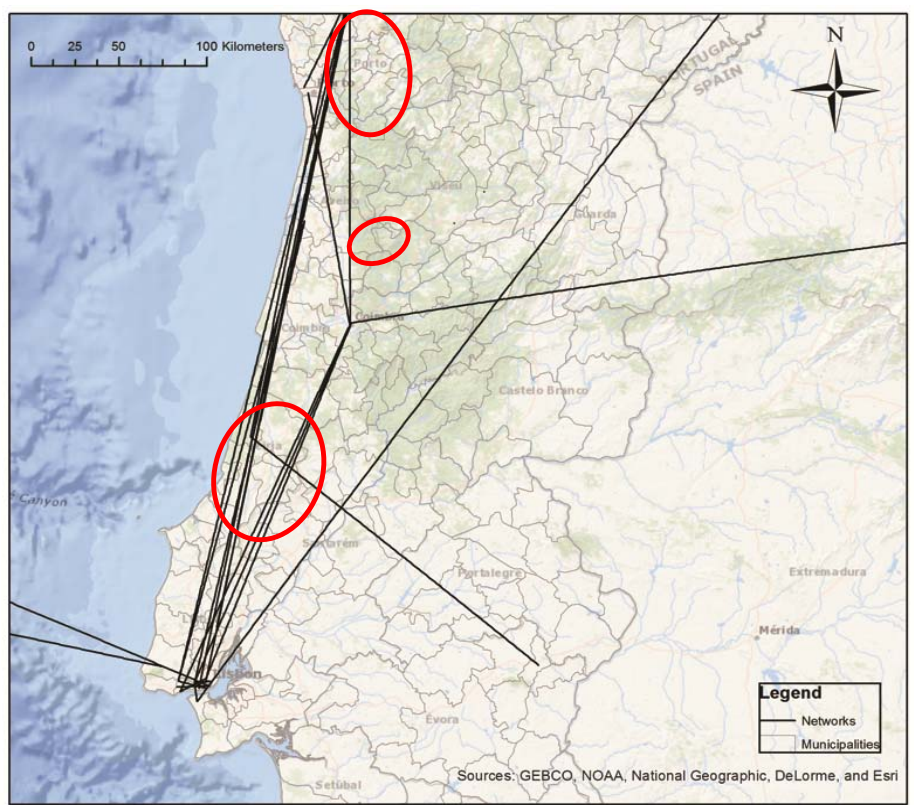

Figure 6. Flow design for internal connections in Portugal 


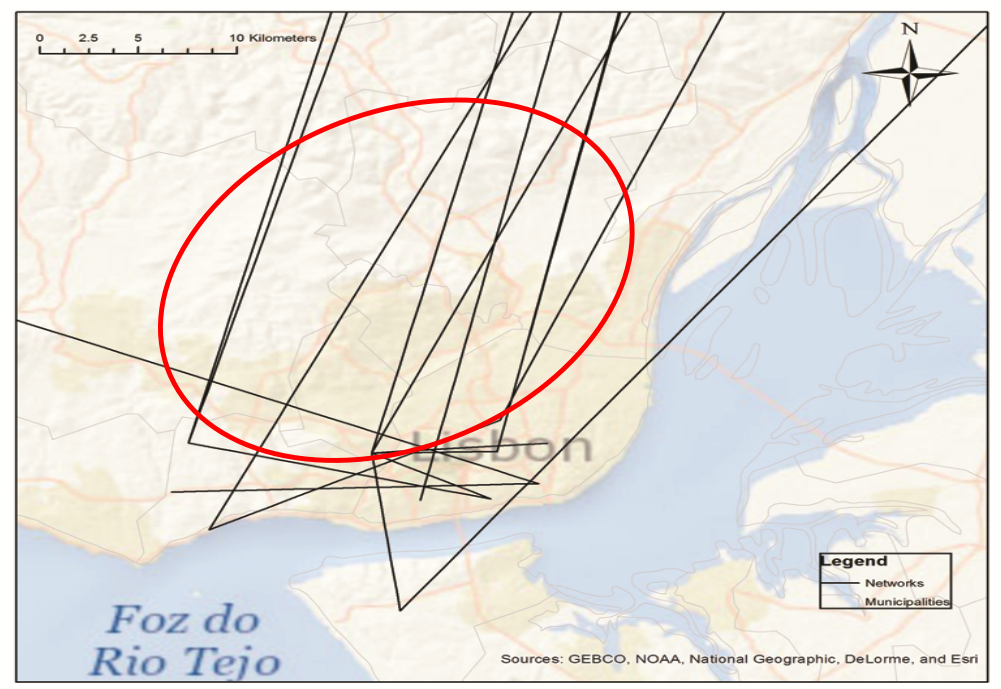

Figure 7. Details of connections in the Lisbon area

\section{CONCLUSION}

The papers has described a spatial-institutional model for mapping out firms' innovative behaviour (FIBE) which is able to offer several advantages to both managers and policy makers who wish to assess companies performance.

Managers of companies or other institutions can compare their individual profiles, reproduced in a geometrical location, with that of the system's average by using a simple tool, and then conclude whether or not they should reinforce specific measures to improve their relative positioning - this may be done by looking strategically for a more rigorous use of the missing attributes.

Policy makers and planners may also find the FIBE to a powerful tool. As pointed out, this study confirms the need to implement tailor-made policies to encourage innovation at the regional level. This is only possible when it is possible to identify the specific choice of attributes used by the set of companies and other institutions. The innovation patterns that they detect may suggest those specific measures which are required to act directly on each described critical success factor, contributing to a new concept of intervention - the regional cluster-architecture, in order to help focus policies for regional development.

Furthermore, the examination of connectivity flows suggests that the emergence of innovation is also a result of the flow intensity, which thus identifies the innovation processes as being spatially determined. Therefore, general policies to promote regional 
innovation will be inefficient able to be entirely efficient if the spatial flows structure is not considered. The resulting paths may create some path dependency; and, in that case, the efficiency of promoting innovation policies in such environments may tend to increase.

\section{REFERENCES}

ACS, Z. J. and AUDRETSCH, D. B. (1991). Innovation and Technological Change. An International Comparison. The University of Michigan Press, Michigan.

ASHEIM, B. T. and ISAKSEN, A. (2003). SMEs and the regional dimension of innovation, in: B. T. Ascheim (ed) Regional Innovation Policy for Small-Medium Enterprises, Edward Elgar, Cheltenham, 21-46.

AUDRETSCH, D.B., KEILBACH, M.C. and LEHMANN, E.E. (2006). Entrepreneurship and Economic Growth. Oxford University Press, Oxford.

CAMAGNI, R. (1991). Introduction: from the local milieu to innovation through corporation networks, in: R. Camagni (ed), Innovation networks: spatial perspectives, Belhaven Press, London and New York, 1-9.

CAMAGNI, R. (1995a). Espace et temps dans le concept de milieu innovateur, in: A. Ralllet, and A. Torre (eds), Économie Industrielle et Économie Spatiale, Economica, Paris, 193210.

CAMAGNI, R. (1995b). Global network and local milieu: towards a theory of economic space, in: S. Conti, E. Malecki and P. Oinas (eds), The Industrial Enterprise and its environment: Spatial Perspectives, Ashgate, Avebury, England, 195-213.

COOKE P., BRACZYK, H.I. and HEIDENREICH, M. (eds) (2004). Regional Innovation Systems: The Role of Governances in a Globalized World, 2nd Edition, Routledge, London.

DEMEY, J.R., VICENTE-VILLARDÓN, J.L., GALINDO, M.P., ZAMBRANO, A.Y. (2008). Identifying Molecular Markers Associated with Classifications of Genotypes by External Logistic Biplot, Bioinformatics, 24: 28-32.

DOLOREUX, D. and PARTO, S. (2005) Regional Innovation Systems: Current discourse and unresolved issues, Technology in Society, 27: 133-153.

FAGERBERG, J. (2003). Schumpeter and the Revival of Evolutionary Economics: an Appraisal of the Literature, Journal of Evolutionary Economics, 13, 125-59.

FISCHER, M.M. (2006). Innovation, Networks and Knowledge Spillovers, Springer, Berlin.

FREEL, M. (1998). Evolution, innovation and learning: evidence from case studies, Entrepreneurship \& Regional Development, 10 (2): 137-149. 
GUSTAFSON, E. (1998) Quantifying Landscape Spatial Pattern: What Is the State of the Art? Ecosystems, 1(2): 143-156

HALL, P. CROUCH C., STREECK W., BOYER R., AMABLE B., and JACKSON G. (2005) Dialogue on Institutional complementarity and political economy, Socio-Economic Review,3: 359-82.

HALL, R. and WEE, M. (1995). The Regions in a Enlarged Europe, in: S. Hardy, M. Hart, L. Albrechts, and A. Katos (eds), An Enlarged Europe. Regions in Competition? Regional Policy and Development, 6. Jessica Kingsley Publishers and Regional Studies Association, London, 8-21.

JANKOWSKI, P. (1995). Integrating geographical information systems and multiple criteria decision-making methods, International Journal of Geographical Information Systems, 9(3): 251-273.

KAISER U. (2002). Measuring Knowledge Spillovers in Manufacturing and Services: An Empirical Assessment of Alternative Approaches, Research Policy, 31 (1): 125-144.

KEEBLE, D. (1997). Small Firms, Innovation and Regional Development in Britain in the 1990s, Regional Studies, 31 (3) 281-293.

KLEINKNECHT, A. and BAIN, D. (1993). New Concepts in Innovation Output Measurements, St Martin's Press, New York.

KNUDSEN, C. (1995). Theories of the Firm, Strategic Management and Leadership, in: C. Montgomery (ed.), Resource-Based and Evolutionary Theories of the Firm, Kluwer, Boston, pp. 179-217.

LANDABASO, M. (1997). The Promotion of Innovation in Regional Policy: Proposals for a Regional Innovation Strategy, Entrepreneurship \& Regional Development, 9 (1) 1-24.

LANGLOIS, R. N. and ROBERTSON, P. L. (1995). Firms, Markets and Economic Change, Routledge, London \& New York.

LESTER, R. (2006). Prospects for Local Innovation Systems, Paper presented at a seminar held in September 2006 at the Department of Economics, National University of Ireland, Galway.

MOILANEN, A. and HANSKI, I., (202) On the use of connectivity measures in spatial ecology, Oikos, 95(1): 147-151.

NIJKAMP, P. (2009a). E Pluribus Unum, Region Direct, 2 (2): 56-65.

NIJKAMP, P. (2009b). Regional Development as Self-Organized Converging Growth, in: G. Kochendorfer and B. Pleskovic (eds), Spatial Disparities and Development Policy, World Bank, Washington DC, pp. 205-282.

NORONHA VAZ, T. (2004). The environmental context for small firms in the EU, in: Noronha Vaz, T., E. Morgan, M. Wigier (eds) Innovation in Small Firms and Dynamics of Local Development, 13-31. 
NORONHA VAZ, T. and CESÁRIO, M. (2008). Driving Forces for Innovation: Are They Measurable? International Journal of Foresight and Innovation Policy, 4 (1-2): 30-50.

NORONHA VAZ, T. and NIJKAMP, P. (2009). Knowledge and Innovation: The Strings between Global and Local Dimensions of Sustainable Growth, Entrepreneurship and Regional Development, 21 (4): 441-457.

PORTER, M.E. (1998). Clusters and the New Economics of Competition, Harvard Business Review, November / December: 77-90.

STIMSON, R., STOUGH, R. and ROBERTS. B. H. (2006). Regional Economic Development, Springer, Berlin.

STOUGH. , R., NIJKAMP, P. and VAZ, M.T.N (eds) (2007). Local Knowledge and Innovation Policy in Government and Policy, Special Issue of Environment and Planning C, 25 (5).

TEIGLAND, R. and SCHENKEL, A. (2006). Exploring the Role of Communities of Practice in Regional Innovation Systems, in: E. Coakes and S. Clarke (eds) The Encyclopaedia of Communities of Practice. In Information and Knowledge Management, Hersley, Idea Group.

VICENTE, P., NORONHA VAZ, T. and NIJKAMP, P. (2010). Institutional Capacity to Dynamically Innovate: An Application to the Portuguese Case, Technological Forecasting \& Social Change, 78 (1): 3-12

VICENTE-VILLARDÓN, J. L., GALINDO-VILLARDON, M. P. and BLAZQUEZZABALlOS, A. (2006), 'Logistic Biplots', in: Greenacre, M. and Blasius, J. (eds.), Multiple correspondence analysis and related methods. Boca, Raton, FL: Chapman Hall, 503-521.

WESTLUND, H., BOLTON, R. (2006). Local Social Capital and Entrepreneurship. Small Business Economics, 21 (2): 77-113.

\section{Websites:}

Community Innovation Survey (CIS),

http://epp.eurostat.ec.europa.eu/cache/ITY_OFFPUB/KS-EM-08-001/EN/KS-EM-08-001-

EN.PDF 